\title{
LEVELS OF INFESTATION ON THREE DIFFERENT PORTIONS OF THE MAIZE COB BY THE WEEVIL SITOPHILUS ZEAMAIS (MOTSCHULSKY)
}

\author{
P. K. Baidoo ${ }^{1}$, M. B. Mochiah ${ }^{2}$ and M. Owusu -Akyaw ${ }^{2}$ \\ ${ }^{1}$ Department of Theoretical and Applied Biology, Kwame Nkrumah University of Science and \\ Technology, Kumasi, Ghana. \\ ${ }^{2}$ Entomology Section, Crop Research Institute, P. O Box 3785, Kumasi, Ghana.
}

\begin{abstract}
The maize weevil, Sitophilus zeamais is a major storage pest of maize that causes significant quantitative and qualitative losses to the farmer. The extent of damage caused by $S$. zeamais to stored maize depends on the initial level of infestation on the field before harvest. The levels of infestations on three different portions of maize cob were studied. Maize was planted during the minor planting season (September-December) of 2008. Maize seeds were sown on 9 plots each measuring $7.0 \mathrm{~m} \times 1.5 \mathrm{~m}$. Matured maize cobs were harvested 110 days after emergence. Ten cobs were randomly selected from each of the plots, dehusked and cut into three portions: top, middle and bottom and stored separately in sealed plastic containers for 5 weeks. Weevils were counted weekly during the storage period. Percent damaged seeds and numbers of holes on damaged grains were counted for each portion. Percent weight loss due to S. zeamais infestation was calculated for the different maize portions. Weevil infestations were recorded on all the portions 1 week after storage. Large numbers of $S$. zeamais were recorded on all the portions at the end of the storage period. The middle portion recorded significantly more $S$. zeamais than the top and bottom portions. Percent damaged seeds; percent weight loss and mean number of holes on damaged seeds did not differ significantly.
\end{abstract}

Keywords: Infested grains, infestation, maize, Sitophilus zeamais, weight loss.

\section{INTRODUCTION}

Maize is an important cereal crop which is widely cultivated Africa by many small-scale farmers as a source of food for man and his animals. Maize production in Africa is however subjected to attack by a number of insect pests. These pests cause considerable damage to the crop on the field and in storage. It is conservatively estimated that about $25 \%$ of maize produced in West Africa annually is destroyed or damaged before reaching the consumer (Setamou et al., 2000). Part of this loss is caused prior to harvesting by weevils, birds and rodents. According to Youdeowei and Service (1986), about $15 \%$ of maize grains harvested in Ghana are lost annually to $S$. zeamais. In Ghana, even though stored maize is protected from attack by $S$. zeamais, the expected result is not achieved because of the warm humid climate which permits high level of insect activity 


\section{Baidoo et al.}

throughout the year. The problem has been compounded by the development of insect resistance to the traditionally used chemical insecticides to protect stored maize (BosquePerez and Buddenhagen, 1992).

Many of the major stored pests of maize infest the crop on the field. Sitophilus zeamais (Motschulsky), (Cardwell et al., 2000; Kim and Kossou, 2003) Sitotroga cerealella (Olivier) and Prostephanus truncatus (Horn) (Bergvinson, 2001) can all infest maize before harvest. S. zeamais appears to infest the maize grain only after the moisture content has dropped to about $30 \%$ (Arnason et al., 1989). S. zeamais is a cosmopolitan pest of grain, preferring whole grain to flour. Prior to the introduction of the larger grain borer $P$. truncatus, $S$. zeamais was reported as the most important pest of stored maize in Africa (Arbogast and Mullen, 1990). Pests' infestations are responsible for changes in chemical composition of stored food, reduction in nutritional values and contamination by harmful compounds (Rajendran and Parveen, 2005).

Some of the factors influencing preharvest infestation in maize include maturity status of the maize grain, husk cover and time of harvest. Both the length and tightness of the husk leaves around the cob will affect infestation by weevils. A tight, long husk has been shown to reduce weevil entry and thus grain damage (Demissie et al., 2008). Damage to the husk and silk by lepidopterous pests such as Eldana saccharina (Walker) and Mucidia nigrivenella (Ragonot) as well as birds will increase the chances of infestation and damage by storage pests. Shelled grains suffer less damage from pests like $P$. truncatus than stored maize on the cob. The opposite is true, however for $S$. zeamas which multiplies in shelled grain than maize stored on the cob with the husk on. Little or no information exists on differential susceptibility of the different zones of the maize cob to $S$. zeamais attack. The study was therefore conducted to determine which portion of the maize cob was most susceptible to destruction by the maize weevil, S. zeamais.

\section{MATERIALS AND METHODS \\ Study Area}

The study was carried out on an experimental farm of plot size $23 \mathrm{~m} \times 6 \mathrm{~m}$ on the Kwame Nkrumah University of Science and Technology Campus, Kumasi. The site is characterized by relatively high annual rainfall of about 730 $\mathrm{mm}$ and annual minimum and maximum temperatures of $21.5{ }^{\circ} \mathrm{C}$ and $32.1{ }^{\circ} \mathrm{C}$, respectively (Addo-Fordjour et al., 2007). The area was divided into 9 plots, each measuring $7.0 \mathrm{~m} \mathrm{x}$ $1.5 \mathrm{~m}$ with $1.0 \mathrm{~m}$ alleys between the plots. There were 3 rows, each containing 10 plants with $0.7 \mathrm{~m}$ between rows and $0.3 \mathrm{~m}$ intra-row spaces. Maize (var. Obaatanpa) was planted at 3 seeds per hole and thinned to 2 seedlings 1 week after emergence. Manual hoeing was done 3 weeks after emergence and subsequently at 3 weeks intervals to control weeds. No fertilizer was applied to the plots.

The crop was harvested at 110 days after emergence. Ten cobs were randomly selected from each of the plots, dehusked and divided into 3 portions: top, middle and bottom and placed separately in labelled plastic containers, covered and stored.

\section{Data collection}

Data collected were number of weevils, number of holes on infested grains and percentage infested grains. Each maize portion was vigorously shaken to dislodge the weevils before counting and their numbers recorded. The insects were killed but the maize cobs were placed in their respective containers. This was done weekly for 5 weeks. At the end of the storage period, the number of exit holes and damaged grains were counted in 100 randomly selected grains from each portion and the means calculated. Subsequently percent weight loss was determined using the method developed by FAO (1985) as follows:

$\%$ weight loss $=\frac{\mathrm{UNd}-\mathrm{DNu}}{\mathrm{U}(\mathrm{Nd}+\mathrm{Nu})} \times 100 \%$ 
where

$\mathrm{U}=$ weight of undamaged grains in the sample

$\mathrm{D}=$ weight of damaged grains in the sample

$\mathrm{Nu}=$ number of undamaged grains in the sample

$\mathrm{Nd}=$ number of damaged grains in the sample

\section{Data analysis}

Data collected were analyzed using SAS, (Version 6) (SAS, 1989). Analysis of variance (ANOVA) was performed and where the differences were significant, the means were separated using Student Neuman-Keuls (SNK) test at $\mathrm{P}<0.05$.

\section{RESULTS AND DISCUSSION \\ Number of weevils}

Weevil infestation was observed on all the maize portions, one week after storage. This was an indication that the cobs were already infested before harvest; however, the numbers were small on all the maize portions. Very small numbers of the pest were recorded in the $2^{\text {nd }}$ and $3^{\text {rd }}$ weeks of storage (Fig. 1). The low numbers of $S$. zeamais was due to the fact that after the initial infestation a minimum of 28 days are needed for eggs laid to develop into adults (Povey and Silby, 1992). Subsequently, relatively larger numbers were recorded for all the portions, with the middle portion recording the largest population increase at the end of the storage period whilst the bottom portion recorded the least number of weevils (Table 1). When the mean infestations were compared the differences were significant $(\mathrm{P}=0.031)$. However, the differences in infestation between the top and bottom portions were not significant (Table 1).

Weevil activities in stored grains may cause various types of losses, including weight loss, reduction in grain quality and promotion of mould growth. Percent Weight loss due to $S$. zeamais infestation ranged from $9.5 \%$ in the bottom portion to $15.3 \%$ in the middle portion (Table 1). However, the differences were not significant $(\mathrm{P}=0.603)$. According to FAO (1991), losses as a result of insect infestation during the short period of storage from harvest to sale at the farm gate ranges between $10 \%$ and $20 \%$. Weevil infestation in the stored maize resulted in damage to the grains. Percent damaged seeds due to feeding by $S$. zeamais were largest in the top portion and least in the bottom portion (Table 1). The differences were not significant $(\mathrm{P}=0.530)$. This indicates that even though weevils entered the cob from the tip, they moved to other parts of the cob causing damage to all regions of the cob.

All the maize portions recorded holes on the grains. The largest number of holes was recorded on grains from the middle portion whilst the bottom portion recorded the least number of holes. The differences were not significant $(\mathrm{P}=$ 0.445). The extent of infestation and feeding by $S$. zeamais determined the number of holes. Feeding activity was most intense in the middle portion resulting in largest number of holes. It appears that the middle portion was the most suitable habitat since this region recorded the largest number of weevils. Even though the middle portion recorded significantly larger number of weevils than other portions, percent damaged grains and number of holes did not differ significantly from those recorded from the other regions of the cob (Table 1).

The length and tightness of the husk leaves around the ear can affect the level of infestation of dried maize cob. A long tight husk has been shown to reduce infestation by $S$. zeamais (Demissie et al., 2008). The maize variety used has short husk leaves with grains filling the cob almost to the tip, thus exposing the grains to damage by pests. Damage done to the husk by lepidopterous pests like E. saccharina and $M$. nigrivenella as well as birds exposed the tips of the cobs, making entry by the weevils easier. Even though infestation was through the tip of the cobs, the middle portion recorded significantly larger weevil numbers because the tip was exposed to harsh environmental conditions such as high temperature and low humidity which did not favour the growth of weevils (Gerard and Arnold, 2002). The weevils thus 


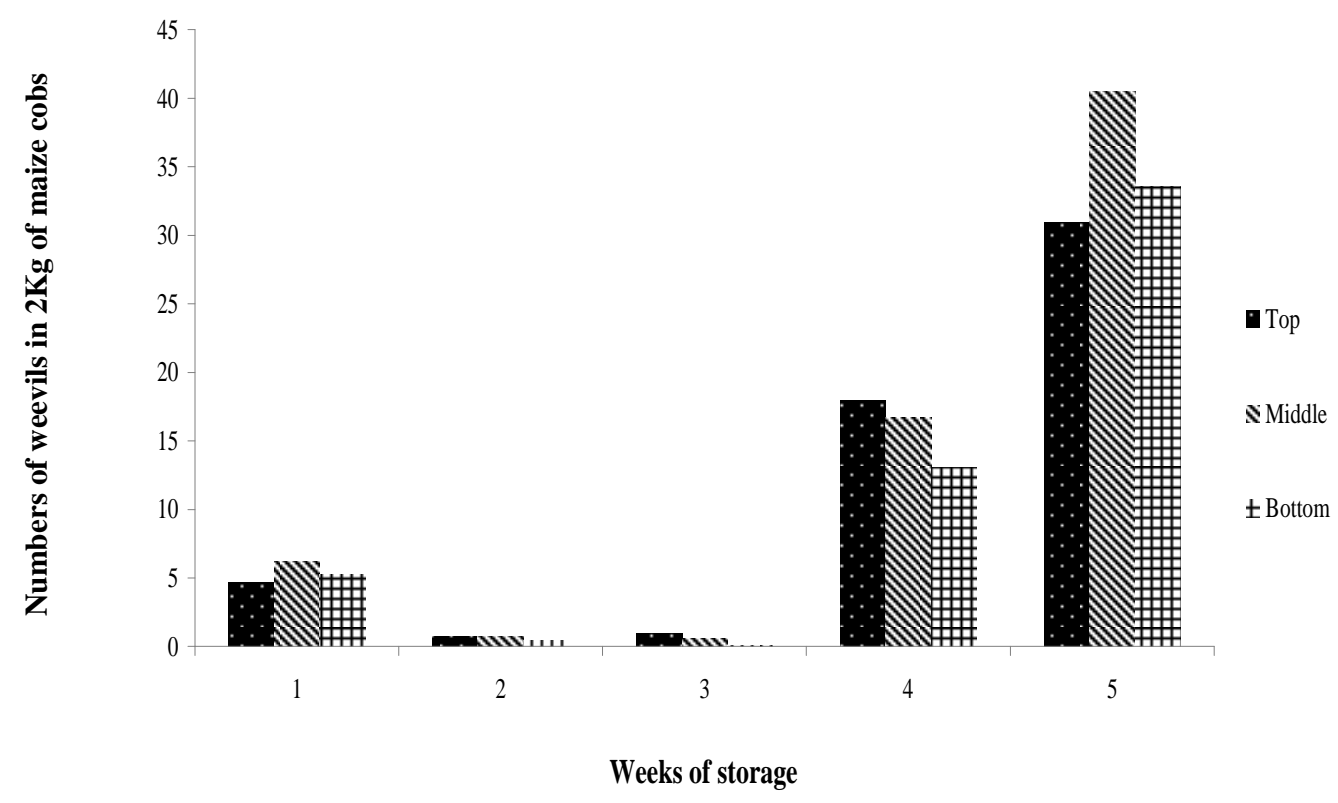

Fig. 1: Weekly numbers of weevils in different maize portions

Table 1: Extent of damage caused to different maize portions by Sitophilus zeamais after 5 weeks of storage, KNUST, minor season 2008.

\begin{tabular}{|c|c|c|c|c|}
\hline Maize Portion & $\begin{array}{l}\text { Mean no. of wee- } \\
\text { vils }\end{array}$ & $\begin{array}{l}\text { \% Damaged } \\
\text { grains }\end{array}$ & \% Weight loss & $\begin{array}{l}\text { Mean no. of } \\
\text { holes/100 grains }\end{array}$ \\
\hline Bottom & $52.6 \pm 10.5^{\mathrm{b}}$ & $10.9 \pm 1.8^{\mathrm{a}}$ & $9.5 \pm 1.8^{\mathrm{a}}$ & $11.6 \pm 1.3^{\mathrm{a}}$ \\
\hline Middle & $68.8 \pm 16.5^{\mathrm{a}}$ & $13.4 \pm 2.2^{\mathrm{a}}$ & $15.3 \pm 3.5^{\mathrm{a}}$ & $16.3 \pm 2.3^{\mathrm{a}}$ \\
\hline Top & $53.6 \pm 9.9^{b}$ & $15.2 \pm 2.1^{\mathrm{a}}$ & $12.5 \pm 2.9^{\mathrm{a}}$ & $14.7 \pm 2.1^{\mathrm{a}}$ \\
\hline
\end{tabular}

Within columns means with the same letter are not significantly different $(\mathrm{P}>0.05)$ 
moved away from the tip to other portions of the cob. The problems associated with the successful control of this pest are compounded by the relatively short life cycle of the pest (Povey and Silby, 1992). Infestation of maize by weevils is not restricted to the field, but storage facilities not protected from insect pest attack can also be a source of infestation. Protection of storage grains from insect pest attack may be achieved with the use of chemical insecticides. However chemical insecticide application could present some health problems if not handled with care.

\section{CONCLUSION}

Maize and other grain crops are often attacked on the field prior to harvesting by insect pests. The fact that adult $S$. zeamais were observed on all the maize portions 1 week after storage was an indication that the cobs were already infested before harvest. The extent of infestation at the time of harvest will influence the level of damage to the grains in storage. Thus prompt harvesting of matured cobs will reduce weevil infestation before storage. Even though all the maize portions were infested, the middle portion recorded significantly more $S$. zeamais than the top and bottom portions. Thus weevils, after infesting the cobs from the tip moved to different regions of the cob.

\section{REFERENCES}

Addo-Fordjour, P., Yeboah-Gyan, K., Lawson, B. W. L. and Akanwariwiak, W. G. (2007). Diversity and distribution of ferns on the campus of Kwame Nkrumah University of Science and Technology, Kumasi, Ghana. Journal of Science and Technology 27, No.1, 35-44.

Arbogast, R. T. and Mullen, M. A. (1990). In teraction of maize weevil and parasitoid (Anisopteromalus calandrae) (Hymenoptera: Pteromalidae) in small bulk of stored corn. Journal of Economic Entomology, 83(6) 2463-2468.

Arnason, J. T., Philogine, B. J. R. and Morand,
P. (Eds.) (1989). Insecticides of plant origin. ACS Symposium Series No. 387, American Chemical Society, Washington DC. USA. 213 pp.

Bergvinson, D. J. (2001). Storage pest resistance in maize. In: Maize Programme. Maize Research Highlights 1999-2000. CIMMYT, Mexico. 32-39.

Bosque-Perez, N. A. and Buddenhagen, I. W. (1992). The development of host-plant resistance to insect pest: Outlook for the Tropics. Pp. 235-249. In: Menken, S B. J. Vissu, J. H. and Herrewijn (eds.) Proceedings of $8^{\text {th }}$ International Symposium. Insect-Pest Relationships. Dordrecht (1992): Kluwer Academic Publishers.

Cardwell, K. F. Kling, J. G, Maziya-Dixon, B. and Bosque-Perez N. A. (2000). Interactions between Fusarium verticilloides and Aspergillus flavus and insect infestation on four maize genotypes in lowland Africa. Phytopathology. 90: 276-284.

Demissie, G., Tefera, T and Tadesse, A. (2008). Importance of husk covering on field infestation of maize by Sitophilus zeamais Motsch. (Coleoptera: Curculionidea) at bako, Western Ethiopia. African Journal of Biotechnology. 7 (20): 3777-3782.

FAO, (1991). Production Yearbook. 45:70-186.

FAO, (1985). Prevention of post harvest food losses. Training Series No. 10 : Rome. Food and Agriculture Organization of the United Nations. 122 pp.

Gerard, P. J. and Arnold, E. D. (2002). Influence of climate regime on clover root weevil adult survival and physiology. New Zealand Plant Protection. 55: 241245

Kim, S. K. and Kossou, D. K. (2003). Re- 
sponses and genetics of maize germplasm resistant to the maize weevil Sitophilus zeamais (Motschulsky) in West Africa. Journal of Stored Products Research. 39: 489-505.

Povey, S. R. and Silby, R. H. (1992). No oviposition plasticity in Sitophilus oryzae. Journal of Stored Product Research, 28: 11-14.

Rajendran, S. and Parveen, H. K. M. (2005). Insect infestation in stored products. Journal of Stored Products Research. 41: 1-30

SAS Institute Inc., (1989) SAS/STAT User's
Guide Version 6, Fourth Edition Vol. 1, SAS Institute, Cary N.C., 943 pp.

Setamou, M., Schulthess, F. Poeling, H. H. and Borgemeister, C. (2000). Monitoring and modeling of field infestation and damage by the ear borer Mucidia nigrivenell (Lepidoptera:Pyralidae) in Benin, West Africa. Journal of Economic Entomology. 93(3) 650-657.

Youdeowei, A and Service, M. W. (1986). Pest and Vector Management in the Tropics. ELBS and Longman Group Ltd. 39pp. 